\title{
Metabolic Profile and Sex Hormone Binding Globulin (SHBG) in Different Reproductive Phases of Czech Women and Their Relations to Weight, Body Composition and Fat Distribution
}

\author{
I. KOSKOVÁ ${ }^{1}$, R. PETRÁSEK ${ }^{2}$, K. VONDRA ${ }^{3}$, M. DUŠKOVÁ ${ }^{3}$, L. STÁRKA $^{3}$ \\ ${ }^{1}$ Faculty of Science, Charles University, ${ }^{2}$ Institute for Clinical and Experimental Medicine, \\ ${ }^{3}$ Institute of Endocrinology, Prague, Czech Republic
}

Received July 30, 2007

Accepted June 13, 2008

\section{Summary}

In our study, 213 healthy Czech women aged 20 to 65 years were examined and divided into fully reproductive, premenopausal, menopausal and postmenopausal groups. In all subjects body composition was determined by classical anthropometry and metabolic profile was assessed. A total of 146 subjects completed 3-year longitudinal study. Total and LDL cholesterol increased and ratio HDL/total cholesterol decreased with age $(p<0.001)$, most significantly in menopause. Triacylglycerols increased only up to menopause. HDL had a very slight trend to decrease in menopause and postmenopause. Fasting blood glucose level increased progressively $(p<0.001)$, in postmenopause frequently exceeded normal range. Higher BMI, total fat mass and central fat indices were associated with higher total and LDL cholesterol, triacylglycerols, C-peptide, insulin and fasting blood glucose level $(p<0.001$; fasting blood glucose level to waist-to-hip ratio: $\mathrm{p}<0.01$ ) and lower $\mathrm{HDL}$ cholesterol $(p<0.001)$. Higher $C$-peptide and insulin were associated with lower HDL cholesterol and higher triacylglycerols $(p<0.001)$. Fasting glucose correlated with LDL cholesterol $(p<0.01)$. Higher SHBG was associated with higher HDL and lower LDL cholesterol $(p<0.001)$. Hormone replacement treatment was related to lower fasting blood glucose level in postmenopausal women $(p<0.01)$. Oral contraception is suggestive of a positive influence on lipid spectrum by increasing the ratio HDL/total cholesterol. Markers of lipid and carbohydrate metabolism are not only age-related, but they are also related to BMI, total fat mass and central fat indices. Therefore, preventive programs should be focused above all on menopausal women.

\section{Key words}

Lipid profile • SHBG • Central adiposity • Menopause

\section{Corresponding author}

I. Kosková, Faculty of Science, Charles University, Albertov 2038/6, 12800 Prague 2, Czech Republic. E-mail: irenako@quick.cz.

\section{Introduction}

Overweight and obesity are well-known risk factors for cardiovascular disease (CVD). Weight is related to blood pressure, total and low density lipoprotein (LDL) cholesterol, triacylglycerols and fasting insulin. Whilst weight increases progressively with age in both pre- and postmenopausal women, in postmenopausal women the increase in weight is associated with increased CVD risk, e.g. a drop in high density lipoprotein (HDL) and a rise in LDL (Owens et al. 1992). Fat distribution plays an important role; central obesity in European women is mostly defined as waist circumference above $80 \mathrm{~cm}$ (Alberti et al. 2006) or waistto-hip ratio (WHR) value over 0.85 and is related to insulin resistance in both obese and non-obese women (Cnop et al. 2002) and non-insulin dependent diabetes (Lundgren et al. 1989), to plasma triacylglycerols, apolipoprotein B, LDL-apoB levels and total/HDL cholesterol ratio, as well as to plasma glucose, insulin, and C-peptide levels measured in the fasting state and after oral glucose load, but it is negatively related to HDL cholesterol levels. Age-related increase in visceral adipose tissue accumulation is a significant factor involved in the deterioration of the CVD risk profile noted in premenopausal women (Pascot et al. 1999). Metabolic syndrome X, well-known correlate of CVD 
risk, is defined by central obesity (in European women: waist $\geq 80 \mathrm{~cm}$; and if body mass index is $>30 \mathrm{~kg} / \mathrm{m}^{2}$ then central obesity can be assumed) plus any two of the following criteria: raised triacylglycerols $\geq 1.7 \mathrm{mmol} / \mathrm{l}$, reduced HDL cholesterol $<1.29 \mathrm{mmol} / \mathrm{l}$ in females or specific treatment for this lipid abnormalities, raised blood pressure: systolic $\geq 130 \mathrm{~mm} \mathrm{Hg}$ or diastolic $\geq 85 \mathrm{~mm} \mathrm{Hg}$ or treatment of previously diagnosed hypertension, raised fasting plasma glucose $\geq 5.6 \mathrm{mmol} / 1$ or previously diagnosed type 2 diabetes (Alberti et al. 2006). Prevalence of metabolic syndrome $X$ raises with age, especially in postmenopausal women (Park et al. 2003) and hyperandrogenemia and low sex hormone binding globulin (SHBG) are frequently found in such patients (Reinecke et al. 2002). Study on 26 Czech women with impaired glucose tolerance proved higher weight, thoracic mesosternal circumference and higher fat percentage assessed according to Pařízková (1977). Women with WHR over 0.80 had higher diastolic blood pressure and higher body mass index (BMI) compared to women with WHR value $\leq 0.80$ (Pobišová et al. 1990). Waist circumference and triacylglycerols were the strongest correlates of insulin resistance in a study on 347 American men and women, however, obese subjects with BMI up to 46 participated in the study (Carr et al. 2004).

A decrease in estrogen/androgen ratio around menopause is related to fat centralization, insulin resistance (Seed 2002) and hyperinsulinemia (Golden et al. 2004). Increase in luteinizing/follicle-stimulating hormone ratio, which is a common finding in obese women, together with hyperinsulinemia and a decrease in SHBG leads to hyperandrogenemia, which is even more evident in central obesity (Vondra and Stárka 1999). SHBG is negatively related to total body fat, upper-body adiposity, fasting serum glucose, insulin and triacylglycerols, but positively to HDL cholesterol (Haffner et al. 1992). A negative correlation of SHBG to anthropometric central fat indices - waist and sagittal diameter at the L4 level - has also been proved in Czech women (Hainer et al. 2002). Low SHBG has also been identified as an independent CVD risk factor (Reinecke et al. 2002).

Physical activity decreases both BMI and central fat accumulation (Gilliat-Wimberly et al. 2001) and can partly counterbalance the negative age-related changes in lipid spectrum and increase in BMI by diminution of HDL decrease. The changes in lipids due to physical activity are largely independent of changes in body weight (Owens et al. 1992).
Studies are not always concordant in the dynamics of weight and fat distribution as well as in their relation to metabolic parameters around menopause and may be population-specific. Such studies on large samples of Middle European women are not available.

A middle-sized sample of healthy Czech women was examined anthropometrically and the metabolic and endocrine characteristics were assessed. Weight increased progressively through fully reproductive years up to menopause with suggestive acceleration around menopause. This weight increase was probably greater than in other European populations. Fat tissue weight and fat percentage increased progressively up to early postmenopause. In postmenopause, only a relative decrease in lean components was evident. No fat centralization was proved in fully reproductive women, while it was suggestive in premenopausal women in cross-sectional data. Fat centralization was clearly proved in menopausal women, but still with significant gluteofemoral fat deposition, and a tendency was observed in postmenopausal women. The influence of hormone replacement therapy (HRT) on anthropometric parameters was not proved; oral contraception (OC) use was related to lower WHR in premenopausal women (Kosková et al. 2007a,b).

The anthropometric indices are quite easy to assess without any risk for the patient and the relation to CVD is evident. It can be thus very helpful to use them in daily clinical practice and some of them also by educated population itself to identify candidates for further examinations and prevention. As some anthropometric characteristics can be population-specific and there are no studies on large samples of Middle-European women, the aim of this study was to provide complex data on the relations of anthropometric characteristics to laboratory parameters in a middle-sized cohort of Middle-European women.

\section{Methods}

Subjects were outpatients of gynecological consultations in Prague, healthy Czech women aged 20-65 years, with BMI below 35, who had not been treated for diabetes, CVD, dyslipidemia, endocrine disturbances or other serious diseases. Treatment modifying body composition was one of the excluding criteria, however, oral contraception (OC) and hormone replacement therapy (HRT) had no influence on the choice of subjects thus representing the real situation of 
healthy Czech women living in Prague. OC/HRT users were defined as women who were taking such therapy at the time of examination; the length of the treatment was ignored. Age intervals representing each reproductive phase of average Middle-European women were established (Živný 1999) and women were accepted to have about 50 persons in each group: fully reproductive group aged 20 -36 years $(n=58$, mean age $26.89 \pm 4.69,37$ OC users), premenopausal women aged 38-45 years $(\mathrm{n}=48$, mean age $42.54 \pm 2.50,11$ OC users), menopausal women aged $48-54$ years $(\mathrm{n}=62$, mean age $51.34 \pm 2.51$, 20 HRT users) and postmenopausal women aged 55-65 years $(\mathrm{n}=45$, mean age $59.53 \pm 2.71,14$ HRT users). All subject were contacted again 3 years later, 146 out of 213 continued the study; baseline characteristics of the 146 subjects cohort was the following: fully reproductive group ( $\mathrm{n}=34, \quad 26.96 \pm 4.47$ years, 23 OC users), premenopausal ( $\mathrm{n}=34,42.23 \pm 2.78$ years, 10 OC users), menopausal ( $\mathrm{n}=45,51.56 \pm 2.61$ years, 20 HRT users) and postmenopausal group $(\mathrm{n}=33,59.55 \pm 2.82$ years, 11 HRT users). OC/HRT users in the longitudinal study were defined as women who were taking OC/HRT at the time of the second examination in 2003. However, most subjects had been on the same or similar therapy before the beginning of the study in 2000. The study protocol was reviewed and accepted by the Ethics Committee of the General University Hospital in Prague 2; informed consent was given by all the subjects.

After a questionnaire and a medical interview the subjects underwent anthropometric examination done by the same investigator. The examination was carried out in morning hours; subjects were in underwear and without shoes. Weight was assessed with medical scales to the nearest $0.1 \mathrm{~kg}$, heights with anthropometer in standing position to the nearest $0,1 \mathrm{~cm}$ - body height, height of suprasternal, iliocristal, iliospinal, symphysion points from floor; widths with pelvimeter and kefalometer to the nearest $0.1 \mathrm{~cm}$ - biacromial, transverse diameter of the chest, bicristal and bispinal width, sagittal diameter of the chest, width of the distal humeral and femoral epiphysis, ankle and wrist width. Circumferences were determined with a flexible tape to the nearest $0.1 \mathrm{~cm}$ - mesosternal chest circumference, abdominal circumference at the level of umbilicus, waist at the minimal point between the xiphoid process and superior iliac crest, gluteal (hip) over the widest part of the hip region, relaxed arm, contracted arm, maximum circumference of the forearm, thigh circumference under gluteal muscle and median thigh circumference and calf maximum circumference. Fourteen skinfolds' thickness were assessed with Best's calipers to the nearest $0.5 \mathrm{~mm}-$ facial, below the chin, on the chest I and II, suprailiacal, abdominal, over the patella, over the biceps, forearm I, over the triceps, subscapular, on the thigh over the quadriceps, on the calf I and II. Measured data were processed by the ANTROPO program and the following quantities were used for further statistical analysis: total fat percentage by the method of Pařízková (1977), sum of 10 skinfolds: facial, below the chin, on the chest I and II, over the triceps, subscapular, abdominal, suprailiacal, over the patella and on the calf I, BMI: weight/(height in $\mathrm{m})^{2}$, WHR: waist / hip circumference, absolute (in $\mathrm{kg}$ ) and relative (in \%) weight of bone, muscle, fat and residue according to Matiegka. The absolute and relative values of the components were corrected by the difference between the real and calculated weight (Bláha et al. 1986).

Blood was taken after $12 \mathrm{~h}$ fasting, in women having their menstrual cycle in the early follicular phase of the cycle, between day 1 and 7 since the beginning of period. The blood sample was taken with maximum delay of 1 month after the anthropometric examination.

Serum was examined for glucose (only in 2000) and lipid profile (total cholesterol, LDL cholesterol, HDL cholesterol) by absorption spectrophotometry, HDL/total cholesterol ratio was calculated, triacylglycerols were assessed by enzymatic method. Insulin and C-peptide were assessed by radioimmunoassay (RIA) and SHBG by radiometric immunoanalysis (IRMA).

Means and standard deviations were calculated for all the parameters in all groups. Pearson's or Spearman's correlation coefficient are used to define linear relationships between the respective parameters. T-test was used to test the differences between groups for parameters with normal distribution, Wilcoxon signedrank test was used for comparison of two measurements of the same parameter in the longitudinal study. Twosample t-test and Mann-Whitney non-parametric test, respectively, were used for comparison of two independent groups. A comparison of age groups was done by one-way analysis of variance. Groups defined by both age and OC/HRT use were tested using two-way analysis of variance. Both tests were completed with Bonferroni method for multiple comparisons.

Baseline data, e. g. data collected in 2000 on 213 subjects were first evaluated as a transversal study. Data collected in 2003 on 146 subjects are compared to the baseline data of the same women as a longitudinal study. 
Table 1. Lipid and carbohydrate profile in the different reproductive phases and correlation to age for the whole sample.

\begin{tabular}{llllll}
\hline & FR & PM & M & PM & $\begin{array}{l}\text { Correlation } \\
\text { to age }\end{array}$ \\
\hline T-Ch (mmol/l) & $5.19 \pm 0.01$ & $5.71 \pm 1.01$ & $6.00 \pm 1.0$ & $6.55 \pm 1.13$ & $0.44^{* * *}$ \\
HDL (mmol/l) & $1.58 \pm 0.37$ & $1.58 \pm 0.39$ & $1.53 \pm 0.36$ & $1.55 \pm 0.36$ & -0.06 \\
LDL (mmol/l) & $3.09 \pm 0.83$ & $3.48 \pm 0.72$ & $3.81 \pm 0.946$ & $4.39 \pm 1.15^{\#}$ & $0.42^{* * *}$ \\
HDL/T-Ch (\%) & $30.90 \pm 6.60$ & $28.20 \pm 7.20$ & $26.37 \pm 8.24$ & $24.60 \pm 7.40$ & $-0.33^{* * *}$ \\
$T G(g / l)$ & $1.15 \pm 0.49$ & $1.25 \pm 0.74$ & $1.59 \pm 1.19$ & $1.53 \pm 0.60$ & $0.22^{* *}$ \\
FBG (mmol/l) & $4.67 \pm 0.54$ & $4.76 \pm 0.58$ & $4.77 \pm 0.57$ & $5.19 \pm 0.63$ & $0.25^{* * *}$ \\
$C$ - peptide (pmol/l) & $0.69 \pm 0.27$ & $0.71 \pm 0.42$ & $0.78 \pm 0.42$ & $0.86 \pm 0.34$ & $0.16^{*}$ \\
Insulin (mIU/l) & $7.32 \pm 3.75$ & $7.79 \pm 6.08$ & $8.32 \pm 10.34$ & $7.48 \pm 4.17$ & 0.01
\end{tabular}

Data are mean $\pm S D$, significant differences of the mean values compared to the previous "younger" group are marked by ${ }^{\#}(P<0.05)$ or \#\#\# $(P<0.001)$. The last column shows the correlation of each parameter to age for the whole sample and the significance level of its correlation coefficient: $* * * \mathrm{P}<0.001, * * \mathrm{P}<0.01, * \mathrm{P}<0.05$. FR - fully reproductive, FBG - fasting blood glucose level, $\mathrm{HDL}-$ high density lipoprotein cholesterol, LDL - low density lipoprotein cholesterol, M - menopausal, PostM - postmenopausal, PreM premenopausal, T-Ch - total cholesterol, TG - triacylglycerols.

Table 2. LH, FSH, SHBG and fasting blood glucose level in the different reproductive phases and influence of OC/HRT.

\begin{tabular}{|c|c|c|c|c|}
\hline & & \multicolumn{2}{|l|}{ PreM } \\
\hline & OC, $\mathbf{n}=\mathbf{3 7}$ & no $O C, n=21$ & $\mathrm{OC}, \mathrm{n}=11$ & no $\mathbf{O C}, \mathbf{n}=37$ \\
\hline$L H(I U / l)$ & $4.7 \pm 2.6$ & $7.0 \pm 3.9$ & $7.8 \pm 5.1$ & $8.2 \pm 7.4$ \\
\hline FSH (IU/l) & $7.0 \pm 3.1$ & $6.3 \pm 2.4$ & $9.5 \pm 8.6$ & $12.2 \pm 12.6$ \\
\hline SHBG (nmol/l) & $140.0 \pm 68.0$ & $72.3 \pm 50.5 * * *$ & $103.4 \pm 53.6$ & $73.1 \pm 41.4$ \\
\hline \multirow[t]{3}{*}{$F B G(\mathrm{mmol} / \mathrm{l})$} & $4.65 \pm 0.52$ & $4.69 \pm 0.59$ & $4.83 \pm 0.67$ & $4.74 \pm 0.54$ \\
\hline & $\mathbf{M}$ & & PostM & \\
\hline & HRT, $n=20$ & no HRT, $n=42$ & HRT, $n=14$ & no $H R T, n=31$ \\
\hline$L H(I U / l)$ & $28.7 \pm 23.8$ & $28.9 \pm 24.3$ & $37.1 \pm 20.0$ & $33.2 \pm 13.5$ \\
\hline FSH (IU/l) & $40.2 \pm 28.9$ & $40.7 \pm 34.6$ & $49.0 \pm 18.8$ & $65.7 \pm 27.8$ \\
\hline SHBG (nmol/l) & $75.0 \pm 43.5$ & $75.3 \pm 45.8$ & $51.6 \pm 23.1$ & $55.0 \pm 24.9$ \\
\hline$F B G(\mathrm{mmol} / \mathrm{l})$ & $4.68 \pm 0.51$ & $4.81 \pm 0.60$ & $4.77 \pm 0.24$ & $5.44 \pm 0.88 * *$ \\
\hline
\end{tabular}

Data are mean $\pm \mathrm{SD}$, significant differences between $\mathrm{OC} / \mathrm{HRT}$ users and non-users are marked: $* * * \mathrm{P}<0.001, * * \mathrm{P}<0.01, * \mathrm{P}<0.05$. FR - fully reproductive, FSH - follicle stimulating hormone, FBG - fasting blood glucose level, HRT - hormonal replacement treatment, LH - luteinizing hormone, M - menopausal, OC - oral contraception, PostM - postmenopausal, PreM - premenopausal, SHBG - sex hormone binding globulin.

\section{Results}

Baseline data (Table 1) were first analyzed as a cross-sectional study. Total and LDL cholesterol increased significantly with age $(r=0.44$ and $r=0.42$, respectively, $\mathrm{p}<0.001$ ), the difference between the groups being significant only for LDL in the menopausal and postmenopausal women $(\mathrm{p}<0.05)$. HDL level was not age-related, triacylglycerols increased slightly up to menopause and tended to decrease in postmenopausal women. OC/HRT influence on lipid profile was not proved in this cohort; postmenopausal women on HRT had non-significantly lower total and LDL cholesterol, triacylglycerols and higher HDL.

Fasting serum glucose increased with age $(\mathrm{r}=0.25, \mathrm{p}<0.001)$, raised slightly up to menopause and the postmenopausal group showed a significant increase $(\mathrm{p}<0.001) \quad$ with frequent pathological values. C-peptide increased slightly with age $(r=0.16, p<0.05)$, insulin did not correlate to age, and its increase was 
Table 3. Significant correlations of carbohydrate and lipid metabolism parameters to anthropometric characteristics: BMI, fat \%, total fat, abdominal, thoracic and waist circumferences, abdominal and chin skinfold and sum of 10 skinfolds.

\begin{tabular}{|c|c|c|c|c|c|c|c|c|c|}
\hline & Insulin & C-peptide & FBG & HDL/T-Ch & TG & HDL & LDL & T-Ch & SHBG \\
\hline \multirow[t]{2}{*}{$B M I$} & 0.36 & 0.43 & 0.33 & -0.50 & 0.35 & -0.39 & 0.38 & 0.29 & -0.29 \\
\hline & $* * *$ & $* * *$ & $* * *$ & $* * *$ & $* * *$ & $* * *$ & $* * *$ & $* * *$ & $* * *$ \\
\hline \multirow[t]{2}{*}{ Fat $\% P$} & 0.28 & 0.33 & 0.32 & -0.45 & 0.31 & -0.32 & 0.36 & 0.30 & -0.42 \\
\hline & $* * *$ & $* * *$ & $* * *$ & $* * *$ & $* * *$ & $* * *$ & $* * *$ & $* * *$ & $* * *$ \\
\hline \multirow[t]{2}{*}{ Fat $\% M$} & 0.26 & 0.30 & 0.31 & -0.43 & 0.25 & -0.31 & 0.37 & 0.31 & -0.39 \\
\hline & $* * *$ & $* * *$ & $* * *$ & $* * *$ & $* * *$ & $* * *$ & $* * *$ & $* * *$ & $* * *$ \\
\hline \multirow[t]{2}{*}{ Total fat } & 0.38 & 0.40 & 0.31 & -0.47 & 0.33 & -0.37 & 0.36 & 0.29 & -0.38 \\
\hline & $* * *$ & $* * *$ & $* * *$ & $* * *$ & $* * *$ & $* * *$ & $* * *$ & $* * *$ & $* * *$ \\
\hline \multirow[t]{2}{*}{ Abdomen } & 0.29 & 0.38 & 0.28 & -0.47 & 0.34 & -0.32 & 0.39 & 0.32 & -0.29 \\
\hline & $* * *$ & $* * *$ & $* * *$ & $* * *$ & $* * *$ & $* * *$ & $* * *$ & $* * *$ & $* * *$ \\
\hline \multirow[t]{2}{*}{ Thorax } & 0.41 & 0.45 & 0.35 & -0.51 & 0.39 & -0.42 & 0.36 & 0.27 & -0.34 \\
\hline & $* * *$ & $* * *$ & $* * *$ & $* * *$ & $* * *$ & $* * *$ & $* * *$ & $* * *$ & $* * *$ \\
\hline \multirow[t]{2}{*}{ Waist } & 0.35 & 0.29 & 0.29 & -0.51 & 0.43 & -0.39 & 0.40 & 0.31 & -0.30 \\
\hline & $* * *$ & $* * *$ & $* * *$ & $* * *$ & $* * *$ & $* * *$ & $* * *$ & $* * *$ & $* * *$ \\
\hline \multirow[t]{2}{*}{$W H R$} & 0.24 & 0.31 & 0.19 & -0.48 & 0.42 & -0.37 & 0.40 & 0.30 & -0.25 \\
\hline & $* * *$ & $* * *$ & $* *$ & $* * *$ & $* * *$ & $* * *$ & $* * *$ & $* * *$ & $* * *$ \\
\hline \multirow[t]{2}{*}{$A b d S F$} & 0.21 & 0.33 & 0.36 & -0.44 & 0.32 & -0.28 & 0.39 & 0.35 & -0.40 \\
\hline & $* * *$ & $* * *$ & $* * *$ & $* * *$ & $* * *$ & $* * *$ & $* * *$ & $* * *$ & $* * *$ \\
\hline \multirow[t]{2}{*}{ Chin $S F$} & 0.26 & 0.32 & 0.29 & -0.42 & 0.32 & -0.26 & 0.39 & 0.35 & -0.41 \\
\hline & $* * *$ & $* * *$ & $* * *$ & $* * *$ & $* * *$ & $* * *$ & $* * *$ & $* * *$ & $* * *$ \\
\hline \multirow[t]{2}{*}{ Sum 10 SF } & 0.32 & 0.35 & 0.32 & -0.47 & 0.31 & -0.35 & 0.38 & 0.31 & 0.45 \\
\hline & $* * *$ & $* * *$ & $* * *$ & $* * *$ & $* * *$ & $* * *$ & $* * *$ & $* * *$ & $* * *$ \\
\hline
\end{tabular}

Significance level of the correlations is marked: $* * * \mathrm{P}<0.001, * * \mathrm{P}<0.01$. Abd SF - abdominal skinfold, BMI - body mass index, Chin SF - skinfold on the chin, Fat \% P - fat percentage by Pařízková, Fat \% M - fat percentage by Matiegka, FBG - fasting blood glucose level, $\mathrm{HDL}$ - high density lipoprotein cholesterol, HRT - hormonal replacement treatment, LDL - low density lipoprotein cholesterol, OC - oral contraception, SHBG - sex hormone binding globulin, Sum 10 SF - sum of 10 skinfolds by Pařízková, T-Ch - total cholesterol, TG triacylglycerols, WHR - waist-to-hip ratio.

evident up to menopause. OC influence on analyzed carbohydrate metabolism markers was not proved, but the power of the test was lower than $80 \%$, HRT use was associated with significantly lower fasting glucose in postmenopausal women $(\mathrm{p}<0.01)$.

Levels of LH and FSH were adequate to the age (Table 2). As expected, SHBG was higher in the fully reproductive women on OC $(p<0.001)$, SHBG did not correlate significantly with age $(r=-0.13, \mathrm{NS}, \mathrm{OC} / \mathrm{HRT}$ users were excluded, $n=131$ ). HRT use in the postmenopausal group was associated with lower fasting blood glucose level $(p<0.01)$. Values of LH, FSH, SHBG and fasting blood glucose level separately in OC/HRT users and non-users are shown in Table 2.

Table 3 shows correlations of metabolic parameters to BMI, fat percentage by Pařízková and Matiegka, fat weight, abdominal, thoracic and waist circumference, WHR, abdominal skinfold and skinfold on the chin, representing the two strongest correlates of all skinfolds, and sum of 10 skinfolds by Pařízková. Higher BMI, fat mass weight and central fat indices were associated with higher total cholesterol, LDL, triacylglycerols, C-peptide, insulin and fasting blood glucose level and lower HDL $(p<0.001$ for all, only fasting blood glucose level to WHR $p<0.01$ ), insulin and $C$-peptide showed the strongest association with thorax circumference. CVD risk indicated by the inverse value of HDL/total cholesterol showed the strongest inverse associations with waist and thorax circumferences, followed by BMI, WHR, abdominal circumference, sum of 10 skinfolds by Pařízková and total fat weight by Matiegka. LDL cholesterol was the second most significant correlate to the above listed anthropometric parameters ( $<<0.001$ all correlations). 
Table 4. Mutual correlations of lipid and carbohydrate metabolism and SHBG.

\begin{tabular}{|c|c|c|c|c|c|c|c|c|}
\hline & T-Ch & HDL & LDL & HDL/T-Ch & TG & FBG & C-peptide & Insulin \\
\hline$H D L$ & 0.12 & & & & & & & \\
\hline$L D L$ & $0.95 * * *$ & $0.95^{* * *}$ & & & & & & \\
\hline$H D L / T-C h$ & $-0.57 * * *$ & $0.72 * * *$ & $-0.69 * * *$ & & & & & \\
\hline$T G$ & $0.29 * * *$ & $-0.43 * * *$ & $0.25 * * *$ & $-0.60 * * *$ & & & & \\
\hline$F B G$ & $0.24 * * *$ & -0.11 & $0.23^{* *}$ & $-0.24 * * *$ & 0.11 & & & \\
\hline C-peptide & $0.21 * *$ & $-0.41 * * *$ & $0.20 * *$ & $-0.46^{* * *}$ & $0.48 * * *$ & $0.22 * *$ & & \\
\hline Insulin & 0.09 & $-0.30 * * *$ & 0.10 & $-0.30 * * *$ & $0.36 * * *$ & $0.21 * *$ & $0.67 * * *$ & \\
\hline$S H B G$ & $-0.20 * *$ & $0.29 * * *$ & $-0.29 * * *$ & $0.38 * * *$ & $-0.15^{*}$ & $-0.17^{*}$ & $-0.19 * *$ & $-0.14^{*}$ \\
\hline
\end{tabular}

Correlations of SHBG only in OC/HRT non-users, mutual correlations of other parameters for the entire cohort. Significance level of the correlations is marked: *** $\mathrm{P}<0.001, * * \mathrm{P}<0.01, * \mathrm{P}<0.05$. FBG - fasting blood glucose level, $\mathrm{HDL}-$ high density lipoprotein cholesterol, LDL - low density lipoprotein cholesterol, SHBG - sex hormone binding globulin, T-Ch - total cholesterol, TG triacylglycerols, WHR - waist-to-hip ratio.

Table 5. Lipid profile, C-peptide and insulin and their changes over 3-year period in the different reproductive phases.

\begin{tabular}{|c|c|c|c|c|}
\hline & FR $n=34$ & & $\operatorname{PreM} n=34$ & \\
\hline Baseline age (years) & $26.96 \pm 4.47$ & & $42.23 \pm 2.78$ & \\
\hline Year of measurement & 2000 & 2003 & 2000 & 2003 \\
\hline$T-C h(\mathrm{mmol} / \mathrm{l})$ & $5.40 \pm 1.14$ & $5.11 \pm 0.91$ & $5.46 \pm 0.91$ & $5.51 \pm 0.99$ \\
\hline$H D L(\mathrm{mmol} / \mathrm{l})$ & $1.68 \pm 0.36$ & $1.65 \pm 0.30$ & $1.48 \pm 0.36$ & $1.53 \pm 0.35$ \\
\hline$L D L(\mathrm{mmol} / \mathrm{l})$ & $3.20 \pm 0.92$ & $2.98 \pm 0.83$ & $3.37 \pm 0.71$ & $3.33 \pm 0.64$ \\
\hline$H D L / T-C h(\%)$ & $31.50 \pm 6.96$ & $32.79 \pm 6.11$ & $27.64 \pm 7.54$ & $28.05 \pm 5.79$ \\
\hline$T G(g / l)$ & $1.22 \pm 0.55$ & $1.08 \pm 0.44$ & $1.27 \pm 0.83$ & $1.20 \pm 0.59$ \\
\hline C-peptide (pmol/l) & $0.69 \pm 0.24$ & $0.60 \pm 0.26$ & $0.80 \pm 0.51$ & $0.77 \pm 0.42$ \\
\hline \multirow[t]{2}{*}{ Insulin $(m I U / l)$} & $7.22 \pm 2.71$ & $6.34 \pm 3.73$ & $8.90 \pm 7.46$ & $8.15 \pm 6.52$ \\
\hline & $M \quad n=45$ & & PostM $n=33$ & \\
\hline Baseline age (years) & $51.56 \pm 2.61$ & & $59.55 \pm 2.82$ & \\
\hline Year of measurement & 2000 & 2003 & 2000 & 2003 \\
\hline$T-C h(\mathrm{mmol} / \mathrm{l})$ & $5.78 \pm 1.08$ & $5.96 \pm 0.79$ & $6.48 \pm 1.23$ & $6.21 \pm 0.99$ \\
\hline$H D L(\mathrm{mmol} / \mathrm{l})$ & $1.53 \pm 0.35$ & $1.54 \pm 0.71$ & $1.58 \pm 0.35$ & $1.54 \pm 0.42$ \\
\hline$L D L(\mathrm{mmol} / \mathrm{l})$ & $3.66 \pm 0.93$ & $3.78 \pm 0.75$ & $4.36 \pm 1.21$ & $4.01 \pm 0.98$ \\
\hline$H D L / T-C h(\%)$ & $27.23 \pm 8.29$ & $25.84 \pm 6.87$ & $25.22 \pm 7.29$ & $25.57 \pm 7.95$ \\
\hline$T G(g / l)$ & $1.37 \pm 0.79$ & $1.44 \pm 0.71$ & $1.62 \pm 0.78$ & $1.62 \pm 0.78$ \\
\hline C-peptide (pmol/l) & $0.74 \pm 0.42$ & $0.83 \pm 0.93$ & $0.88 \pm 0.36$ & $0.91 \pm 0.50$ \\
\hline Insulin (mIU/l) & $8.51 \pm 12.23$ & $8.40 \pm 12.26$ & $7.54 \pm 3.97$ & $10.46 \pm 11.34$ \\
\hline
\end{tabular}

Data are mean \pm SD, FR - fully reproductive, HDL - high density lipoprotein cholesterol, LDL - low density lipoprotein cholesterol, M - menopausal, PostM - postmenopausal, PreM - premenopausal, T-Ch - total cholesterol, TG - triacylglycerols.

Table 4 shows mutual correlations of laboratory markers in the entire cohort, correlation to SHBG does not comprise OC/HRT users: higher fasting glucose was significantly associated with higher total cholesterol $(\mathrm{p}<0.001)$, LDL cholesterol $(\mathrm{p}<0.01)$ and HDL/total cholesterol ratio $(\mathrm{p}<0.001)$, the correlations of glucose to HDL and triacylglycerols were non-significant. C-peptide and insulin showed negative correlations to $\mathrm{HDL}$ 
cholesterol and a positive correlation to triacylglycerols $(p<0.001)$, insulin did not correlate to total and LDL cholesterol. Out of carbohydrate metabolism indices, C-peptide showed the strongest relation to lipid spectrum. Higher SHBG was associated with higher HDL cholesterol and ratio HDL/total cholesterol $(\mathrm{p}<0.001)$, lower total cholesterol $(\mathrm{p}<0.01)$, LDL cholesterol $(\mathrm{p}<0.001)$, triacylglycerols, fasting glucose, insulin (all $\mathrm{p}<0.05)$ and $\mathrm{C}$-peptide $(\mathrm{p}<0.01)$.

Longitudinal study did not reveal any significant changes in lipid spectrum, insulin or C-peptide in any reproductive group. However, there was a trend to lipid spectrum deterioration towards risk lipid pattern in the menopausal group (Table 5).

OC/HRT influence on C-peptide or insulin was not proved in the longitudinal study, but the power of the test was lower than $80 \%$. OC use was associated with higher HDL/total cholesterol in the analysis of the fully reproductive and premenopausal groups together - in OC users this ratio increased by $2.15 \%$, in non-users decreased by $0.39 \%,(p<0.05)$, the same trend was seen in the premenopausal group.

Changes in FSH and LH are concordant with gradual extinction of sexual functions; some of them can be traced already in the premenopausal group. SHBG decreased non-significantly in all groups with the exception of the postmenopausal one, which remained stable.

\section{Discussion}

Transversal data show progressive shift of lipid profile towards more risky one across the groups: the rise in total cholesterol was caused by isolated LDL increase, and consequently increased CVD risk was demonstrated by the increase in HDL/total cholesterol ratio. Triacylglycerols rose only up to menopause, there was even a decreasing trend in postmenopause. HDL was quite stable, no decline was proved in menopause and postmenopause, only a very slight trend may be seen. HDL was the only age-independent lipid marker.

Hormonal changes associated with menopause were proved to raise CVD risk and postmenopause was demonstrated to be an independent CVD risk factor (Lerner and Kannel 1986). Estrogens have a direct effect on vasodilatation and an indirect long-term effect consisting of modulation of the response to endothelial damage and atherosclerotic changes in vessels and an influence on levels of serum lipoproteins and triacylglycerols. Postmenopausal women have higher levels of triacylglycerols, total and LDL cholesterol compared to premenopausal women (Stevenson et al. 1993, Gower et al. 1998), while in some studies HDL levels were significantly lower independently of age, BMI and other potentially confounding variables (Stevenson et al. 1993). Increases in LDL cholesterol and triacylglycerols and declines in HDL cholesterol are greater during perimenopause than postmenopause, whereas increase in fasting glucose level is greater during postmenopause (Matthews et al. 2001). On the other hand, there are also studies indicating no influence of menopause on HDL cholesterol. Beside that, the study proved a relationship of LDL cholesterol to estimated intraabdominal fat in pre- and postmenopausal women and to sum of central skinfolds in pre- but not in postmenopausal women. Triacylglycerols were related only to central adiposity, e. g. sum of central skinfolds and estimated intraabdominal fat. Adjustment for estimated intraabdominal fat decreased menopauserelated differences in levels of total and LDL cholesterol by $44 \%$ and $46 \%$, respectively, and by triacylglycerols levels by $73 \%$. This implies that menopause-related intraabdominal fat accumulation may adversely affect the plasma lipid profile (Gower et al. 1998).

The 3-year longitudinal follow-up did not prove any significant changes in lipid profile, only slight trend to a less risky profile in all groups except for the menopausal one where LDL cholesterol shows a tendency to rise and the ratio $\mathrm{HDL} /$ total cholesterol to decline. This tendency to lipid profile improvement with time in other groups in spite of weight/BMI increase and trend to fat centralization could be explained by positive lifestyle changes in Czech women over the last years. A drop in total cholesterol in Czech population has been confirmed already in Countrywide Integrated Noncommunicable Diseases Intervention Program (CINDI) between the years 1991 and 2000 (Kazmarová and Kodl 2001). Our results support the continuity of this positive change.

We have proved significant positive correlations of total, LDL cholesterol and triacylglycerols to age, BMI, total body fat and indices of central adiposity and negative correlation of HDL cholesterol and HDL/total cholesterol ratio to BMI, total body fat and indices of central adiposity. Physical activity has a positive influence on lipid profile and a decrease in physical activity in most aging women is well-known.

Fasting blood glucose level increases 
significantly with age, most significant increase was proved in postmenopause, mean values of fasting glucose being in normal range in all groups. Only in the postmenopausal group the mean value is close to upper limit and more women with impaired glucose tolerance were found in this group. These data are consistent with other authors (Matthews et al. 2001). C-peptide is less age-dependent and insulin was not age-dependent. Fasting blood glucose level, insulin and C-peptide correlated significantly to BMI, total body fat and central adiposity indices, only fasting blood glucose level showed a relatively weaker correlation to WHR, however, its correlation to waist and abdomen were very important and even more significant than to age. C-peptide and insulin showed negative correlations to HDL and positive correlations to triacylglycerols and fasting glucose. On the other hand, fasting blood glucose level did not correlate to HDL and triacylglycerols, but there was a significant correlation of fasting blood glucose level to LDL cholesterol, total cholesterol and the HDL/total cholesterol ratio. C-peptide showed the strongest relation to lipid metabolism, BMI and central adiposity indices. The relation between central fat and increased fasting glucose already in premenopausal women has also been proved by other authors (Pascot et al. 1999). Previous data on Czech women show increased weight, thoracic mesosternal circumference and higher fat percentage by Pařízková in women with impaired glucose tolerance (Pobišová et al. 1990).

Concordantly with other sources, the relation of SHBG to LDL and HDL cholesterol (women on OC/HRT had been excluded) was also proved in our sample: higher SHBG was associated with lower LDL and higher HDL, both on the same significance level. SHBG is also associated with carbohydrate metabolism parameters (Haffner et al. 1992). SHBG has been identified as independent CVD factor in postmenopausal women (Reinecke et al. 2002). Significant correlations between carbohydrate and lipid metabolism and BMI, total fat and central adiposity indices were found in this sample and they are consistent with metabolic changes brought about by changes of weight, body composition and fat distribution: risk metabolic profile and even metabolic syndrome $\mathrm{X}$ with all health consequences. Estrogens contained in OC increase SHBG and consequently the free testosterone increases. OC users further have lower dehydroepiandrostendione sulphate (DHEAS), prolactin, higher corticosteroid binding globulin and therefore total cortisol, higher thyroxin binding globulin whilst free thyroxin increases very slightly and thus thyroid gland metabolism remains unchanged (Wiegratz et al. 2003). In the longitudinal follow-up of this study a positive influence of $\mathrm{OC}$ on the ratio HDL/total cholesterol was shown: premenopausal OC users show an increase by $2.15 \%$, while non-users showed a decrease by $0.39 \%$ $(p<0.05)$. The same trend was found in the fully reproductive group, these changes being consistent with previous findings (Wiegratz et al. 1998). No significant HRT effect on lipid profile was proved. We would like to point out that as the study was not primarily planned to proof OC/HRT effects, the power of the tests is lower than $80 \%$. However, postmenopausal HRT users showed non-significantly lower total and LDL cholesterol and triacylglycerols and higher HDL cholesterol and fasting glucose. These findings are consistent with other studies (Salpeter et al. 2006). The opinion that women receiving HRT for the relief of menopausal symptoms might also benefit from the cardioprotective effects of restored estrogen levels has been challenged by the results of the first randomized trial of HRT for primary CVD prevention. Results of this study suggested that HRT may further contribute to the increased risk of CVD in postmenopausal women (Rossouw et al. 2002). Recent controlled trials have failed to show a beneficial effect of HRT on the incidence of coronary events and the discrepancy with some previous studies may be explained by the failure to adjust for baseline differences such as socioeconomic status or education. However, actually the over-all benefits of HRT have been recognized to outbalance potential risks for postmenopausal women (Clearfield 2004).

There is evidence of age-related CVD risk, menopause being the most critical period, the unfavorable changes in anthropometric and metabolic parameters associated with CVD risk can be at least partly counterbalanced by healthy initiatives and preventive programs focused on healthier diet and increase in physical activity. It is therefore necessary for the menopausal women to be more involved in such activities.

\section{Conflict of Interest}

There is no conflict of interest.

\section{Acknowledgements}

The study was supported by grant No. NR 9055-4 of the IGA MZCR. Grateful acknowledgements to Mgr. Jelena Skibová from the Statistic department of the Institute of 
Clinical and Experimental Medicine in Prague for statistic analyses. Our thanks go to nurses of functional diagnostic lab of the Institute of Endocrinology for their invaluable contribution to material collection, to heads of labs of Institute for Clinical and Experimental Medicine
Ing. Ludmila Karasová, Ing. Anna Glagoličová and Ing. Petr Stávek, PhD and to lab technicians for samples analyses. We are grateful to all women who participated in the study.

\section{References}

ALBERTI KG, ZIMMET P, SHAW J: Metabolic syndrome - a new world-wide definition. A Consensus Statement from the International Diabetes Federation, Diabet Med 5: 469-480, 2006.

BLÁHA P, ŠEDIVÝ V, ČECHOVSKÝ K, KOSOVÁ A: Anthropometric studies of the Czechoslovak population from 6 to 55 years, Czechoslovak Spartakiade 1985, vol. 1, part 2, Ústřední štáb československé spartakiády, Prague, 1986, pp 139-262.

CARR DB, UTZSCHNEIDER KM, HULL RL, KODAMA K, RETZLAFF BM, BRUNZEL JD, SHOFER JB, FISH BE, KNOPP RH, KAHN SE: Intra-abdominal fat is a major determinant of the National Cholesterol Education Program Adult Treatment Panel III criteria for the metabolic syndrome. Diabetes 538: 2087-2094, 2004.

CLEARFIELD M: Coronary heart disease risk reduction in postmenopausal women: the role of statin therapy and hormone replacement therapy. Prev Cardiol 7: 131-136, 2004.

CNOP M, LANDCHILD MJ, VIDAL J, HAVEL PJ, KNOWLES NG, CARR DB, WANG F, HULL RL, BOYKO EJ, RETZLAFF BM, WALDEN CE, KNOPP RH, KAHN SE: The concurrent accumulation of intra-abdominal and subcutaneous fat explains the association between insulin resistance and plasma leptin concentrations: distinct metabolic effects of two fat compartments. Diabetes 51: 1005-1015, 2002.

GILLIAT-WIMBERLY M, MANORE MM, WOOLF K, SWAN PD, CARROLL SS: Effects of habitual physical activity on the resting metabolic rates and body compositions of women aged 35 to 50 years. $J$ Am Diet Assoc 101: 1181-1188, 2001.

GOLDEN SH, DING J, SZKLO M, SCHMIDT MI, DUNCAN B, DOBS A: Glucose and insulin components of the metabolic syndrome are associated with hyperandrogenism in postmenopausal women: the atherosclerosis risk in communities study. Am J Epidemiol 160: 540-548, 2004.

GOWER BA, NAGY TR, GORAN MI, TOTH MJ, POEHLMAN ET: Fat distribution and plasma lipid-lipoprotein concentrations in pre- and postmenopausal women. Int J Obes Relat Metab Disord 22: 605-611, 1998.

HAFFNER SM, DUNN JF, KATZ MS: Relationship of sex hormone-binding globulin to lipid, lipoprotein, glucose, and insulin concentrations in postmenopausal women. Metabolism 41: 278-284, 1992.

HAINER V, KUNEŠOVÁ M, PAŘÍZKOVÁ J, MIKULOVÁ R, STUNKARD A: Serum cortisol and sex hormone binding globulin (SHBG) levels, body fat distribution and the role of genetic factors in obese females. Sb Lek 4: 471-475, 2002.

KAZMAROVÁ H, KODL M: Risk factors for noncommunicable diseases in the population of the Czech Republic in the relationship to intervention programmes (in Czech), www.szu.cz/czzp/cindi/vrf.html, 2001, accessed 06-03-2007.

KOSKOVÁ I, PETRÁSEK R, VONDRA K, BLÁHA P, SKIBOVÁ J, GLAGOLIČOVÁ A, KARASOVÁ L: Weight, body composition and fat distribution of Czech women in relation with reproductive phase: a cross-sectional study. Prague Med Rep 108: 13-26, 2007a.

KOSKOVÁ I, PETRÁSEK R, VONDRA K, SKIBOVÁ J: Weight, body composition and fat distribution changes of Czech women in the different reproductive phases: a longitudinal study. Prague Med Rep 108: 226-242, 2007b.

LERNER DJ, KANNEL WB: Patterns of coronary heart disease morbidity and mortality in the sexes: a 26-year followup of the Framingham population. Am Heart J 111: 383-390, 1986.

LUNDGREN H, BENGTSSON C, BLOHME G, LAPIDUS L, SJOSTROM L: Adiposity and adipose tissue distribution in relation to incidence of diabetes in women: results from a prospective population study in Gothenburg, Sweden. Int J Obes 13: 413-423, 1989. 
MATTHEWS KA, KULLER LH, SUTTON-TYRRELL K, CHANG YF: Changes in cardiovascular risk factors during perimenopause and postmenopause and carotid artery atherosclerosis in healthy women. Stroke 32: 1104-1111, 2001.

OWENS JF, MATTHEWS KA, WING RR, KULLER LH: Can physical activity mitigate the effects of aging in middle-aged women? Circulation 85: 1265-1270, 1992.

PARK YW, ZHU S, PALANIAPPAN L, HESHKA S, CARNETHON MR, HEYMSFIELD SB: The metabolic syndrome: prevalence and associated risk factor findings in the US population from the Third National Health and Nutrition Examination Survey, 1988-1994. Arch Intern Med 163: 427-436, 2003.

PǍ̌íZKOVÁ J: Body Fat and Physical Fitness. Martinus Nijhoff, The Hague. 1977.

PASCOT A, LEMIEUX S, LEMIEUX I, PRUD'HOMME D, TREMBLAY A, BOUCHARD C, NADEAU A, COUILLARD C, TCHERNOF A, BERGERON J, DESPRES JP: Age-related increase in visceral adipose tissue and body fat and the metabolic risk profile of premenopausal women. Diabetes Care 22: 1471-1478, 1999.

POBIŠOVÁ Z, ZAMRAZIL V, BLÁHA P, PLATILOVÁ H, SIMEČKOVÁ A, TRUNEČKA E, VAVŘEJNOVÁ V, REISENAUER R: Selected anthropometric findings in women with disorders of glucose tolerance with hypertension. Vnitř Lék 36: 521-525, 1990.

REINECKE H, BOGDANSKI J, WOLTERING A, BREITHARDT G, ASSMANN G, KERBER S, VON ECKARDSTEIN A: Relation of serum levels of sex hormone binding globulin to coronary heart disease in postmenopausal women. Am J Cardiol 90: 364-368, 2002.

ROSSOUW JE, ANDERSON GL, PRENTICE RL, LACROIX AZ, KOOPERBERG C, STEFANICK ML, JACKSON RD, BERESFORD SA, HOWARD BW, JOHNSON KC, KOTCHEN JM, OCKENE J: Risks and benefits of estrogen plus progestin in healthy postmenopausal women: principal results From the Women's Health Initiative randomised controlled trial. JAMA 288: 321-333, 2002.

SALPETER SR, WALSH JM, ORMISTON TM, GREYBER E, BUCKLEY NS, SALPETER EE: Meta-analysis: effect of hormone-replacement therapy on components of the metabolic syndrome in postmenopausal women. Diabetes Obes Metab 5: 538-554, 2006.

SEED M: The choice of hormone replacement therapy or statin therapy in the treatment of hyperlipidemic postmenopausal women. Atherosclerosis Suppl 3: 53-63, 2002.

STEVENSON JC, CROOK D, GODSLAND IF: Influence of age and menopause on serum lipids and lipoproteins in healthy women. Atherosclerosis 98: 83-90, 1993.

VONDRA K, STÁRKA L: Obesity viewed by an endocrinologist. In: Aktuální endokrinologie (in Czech), STÁRKA L et al. (eds), Maxdorf, Prague, 1999, pp 217-242.

WIEGRATZ I, KUTSCHERA E, LEE JH, MOORE C, MELLINGER U, WINKLER UH, KUHL H: Effect of four different oral contraceptives on various sex hormones and serum-binding globulins. Contraception 6: 25-32, 2003.

WIEGRATZ I, JUNG-HOFFMANN C, GROSS W, KUHL H: Effect of two oral contraceptives containing ethinyl estradiol and gestodene or norgestimate on different lipid and lipoprotein parameters. Contraception 2: 83-91, 1998.

ŽIVNÝ J: Hormonal replacement therapy. In: Aktuální endokrinologie (in Czech), STÁRKA L et al. (eds), Maxdorf, Prague, 1999, pp 579-597. 